\title{
Intermediation by aid agencies ${ }^{1}$
}

\author{
Colin Rowat $^{2} \quad$ Paul Seabright ${ }^{3}$
}

October 21, 2005

${ }^{1}$ Revises Department of Economics Discussion Paper 04-22. The authors thank Ralph Bailey, Mayling Birney, Jayasri Dutta, Guido Friebel, Chirantan Ganguly, Martin Jensen, Alejandro Manelli, Herakles Polemarchakis, Indra Ray, Stuart Taylor, Jennifer Tobin, Thierry Verdier and seminar participants in ECARES, Edinburgh, Harvard's Center for International Development, Milan and the Université Libre de Bruxelles. Rowat thanks l'Institut d'Economie Industrielle for its hospitality.

${ }^{2}$ Department of Economics, University of Birmingham

${ }^{3}$ Institut d'Economie Industrielle, Université des Sciences Sociales and CEPR 


\begin{abstract}
This paper models aid agencies as financial intermediaries that do not make a financial return to depositors, whose concern is to transfer resources to investor-beneficiaries. This leads to a problem of verifying that the agency is using donations as intended. One solution to this problem is for an agency to employ altruistic workers at below-market wages: altruistic workers, who can monitor the agency's activities, would not work at below-market rates unless it were genuinely transferring resources to beneficiaries. We consider conditions for this solution to be incentive compatible. In a model with pure moral hazard, observability of wages makes incorporation as a not-forprofit firm redundant as a commitment device. In a model with both moral hazard and adverse selection, incorporation as a not-for-profit firm can serve as a costly commitment mechanism reassuring donors against misuse of their funds. Hiring a worker of low ability can also be a valuable commitment device against fraud.

Key words: signalling, non-profit, wage differential, donations, altruism, two-sided market
\end{abstract}

JEL classification numbers: D210, D640, J310, L310 
The aid agencies themselves in this difficult environment do not have much incentive to achieve results, since the results are mostly unobservable. ... Virtually all observers of aid agencies agree that they allocate too little effort either to insuring that loan conditions were actually observed or to later evaluation of loan effectiveness. ... Aid agencies face a peculiar incentive problem: they spend one group of people's money on a different group of people. The intended beneficiaries have almost no voice in how the money is spent. (Easterly (2003))

\section{Introduction}

Aid agencies, like banks, connect finance with projects. We can therefore think of aid agencies as a kind of financial intermediary, albeit of a rather special kind. Two things in particular make them special. First, unlike in the case of banks, it is not typically expected that any share of a project's returns be returned to its financiers. This makes it difficult for donors to assess the efficiency of their intermediary: while the interest rate a bank offers to depositors can be compared to those of other banks, donors to an aid agency have no immediately observable signal of the results of the agency's intermediation activity. Secondly, even if alternative signals of project returns are available (such as audited accounting data), one characteristic of an aid project is that its true social returns may not be fully or even partially captured in flows of finance, either because the project generates externalities that are not easily appropriable or because the value of such financial flows as are generated consists chiefly in their accruing to poor individuals whose weight in a social welfare function is high.

Not all intermediary organizations need to worry about providing signals between the individuals on the two sides of their market. Some intermediaries, such as dating agencies, exist to put individuals in contact with each other; once this has been done the contact itself provides the signal. Other organizations also act as intermediaries between a donor and a distant recipient without necessarily providing feedback to the donor. Postal services and florists generally do not, except at a higher price, inform donors when their orders have been delivered. In these cases, however, the donor and recipient may already know each other, and have their own channels for providing feedback.

Aid agencies, however, face the same predicament of distance and anonymity as financial institutions like banks, but without the feedback signal available to banks. This paper addresses the question of how aid agencies manage to 
signal quality to potential donors. In doing so, it attempts to exploit the stylised facts that such agencies are typically incorporated as non-profits (NPs), and their professional staff may be paid at below market wages. The role of the former observation has already been explored in the literature: Glaeser and Shleifer (2001) and related papers assume that it is more expensive for those in charge of a NP to appropriate its resources (as they are required to do so through perks) than it is for those in charge of a for-profit (FP), since the latter may use dividends or other cash payouts. Thus, NP status imposes an inefficiency that weakens the incentives to appropriate the organization's resources for private gain. ${ }^{1}$

This paper's contribution lies in its development of the second observation. Before explaining how we do so, we review the empirical literature. In brief, early findings of wage discounts for employees of US domestic NPs (e.g. hospitals, universities, etc.) seem to disappear when self-selection, hours of work, etc. are controlled for. As a whole, however, this literature has not studied the fully two-sided markets of interest to us, in which the possibilities for feedback between donor and recipient are negligible. There is some empirical, and much anecdotal, evidence that a NP wage discount exists in this sector.

Handy and Katz (1998) report results suggesting that "nonprofits tend to pay their managers a lower wage than [do] for-profits". The results on which they report are drawn from US NP organizations. ${ }^{2}$ Their explanations for lower wages for professionals appeal to two factors: trust is more important in the environments in which they work, which are marked by asymmetric information; and managers may self-select on the basis of personality traits.

Mocan and Tekin (2003) argue, instead, that "the empirical evidence on the nonprofit wage differential is ambiguous. Most of this ambiguity seems to stem from inadequate data sets". In contrast, they control for self-selection into the child care sector in four US states as well as for unobserved worker heterogeneity. Doing so, they find wage premia associated with NPs: "nonprofit compensation differential is $8 \%$ for full-time workers and $10 \%$ for parttime workers." They note theoretical arguments for premia and for discounts: NP managers may 'capture' the organization, and reward themselves more highly; NP managers may derive more job satisfaction from 'doing good', and require less pay.

An addition theoretical argument for NP wage premia is provided by

\footnotetext{
${ }^{1}$ FPs can, of course, write constitutions prohibiting such disbursals.

${ }^{2}$ Preston (1989) include "hospitals; health services; [schools and universities]; libraries; museums, art galleries, and zoos; religious organizations; welfare services; residential welfare facilities; and nonprofit membership organizations" - but not aid agencies. Frank (1996) does not indicate how it classified employers a FP, NP or government.
} 
François (2003). He considers workers who receive utility from the level of provision of a public good: they do not care how that good is provided, thus their utility is not of what is sometimes called the 'warm glow' kind, namely dependent on the character of their own involvement in the desired outcome. Effort can be induced in one of two ways: a supervision technology which solves the moral hazard problem at a fixed cost; or a contract paying a wage premium if the contracted effort is supplied, firing the worker otherwise. Under the latter, the managers of FPs are induced to supply more remedial effort if the worker shirks: they care not just about the effect of shirking on the level of public good provision, but also on their profits. Inverting the usual story, the costs of shirking in a NP are greater: not just loss of an efficiency wage, but a greater reduction in the public good. The efficiency wage paid by NPs is therefore less than that required of FPs, causing the FPs to be competed out of the sectors that do not use the supervision technology. Therefore NPs will predominate in the sectors that pay a wage premium. Note, however, that controlling for the production technology and for effort levels, workers in NPs are still being paid less than those in FPs would be paid for doing strictly identical work, even if actual empirical data might not make it possible to control accurately for these differences.

Ruhm and Borkoski (2002) study the US Current Population Survey Outgoing Rotation Groups and survey the literature. They find no strong evidence of 'labour donation'.

In the developmental context, Reinikka and Svensson (2004) estimate the relative behaviour of health care providers in Uganda. They find that religious NPs pay their medical staff at below market rates, but are more likely to provide pro-poor and public health care, charging lower rates for similar levels of (observable) quality.

Somewhat further afield, Buraschi and Cornelli (2003) study donations to the English National Opera. Donations seem to be motivated by a perception that the donor is pivotal to providing a production funded by the donations.

Our own model supposes that donors to an aid agency cannot observe directly the quality of the agency's work. However, they can observe the remuneration enjoyed by the agency's employees. This need not be interpreted literally as an observation of the wage itself: remuneration may be non-pecuniary. For example, as monks may take vows of poverty, charities may visibly forgo luxury. Thus, most generally, we allows donors to observe some data on overheads. This figures appear both in annual reports and are frequently cited by charities when fund-raising. From these data, donors draw inferences about the uses to which the charities are putting the funds that they cannot observe. The question is whether signals, such as wages and organisational form choice, are reliable in equilibrium. 
We consider a one period world in which there are three, potentially similar agents: workers, who may be selfish or altruistic, founders, who may also be selfish or altruistic, and donors, who are always altruistic. By altruistic we simply mean that they care about the results of the agency's actions (this is not the same as a 'mission' in the sense of Besley and Ghatak (2003), since the utility is a function of equilibrium outcomes rather than the type of the organization). The objective functions of altruistic agents are additively separable in consumption and the altruistic component; this second term is omitted from those of selfish agents.

The founder (principal) hires a worker (agent) to manage projects on her behalf. The worker then performs two types of project for the principal: actual development work in a poor locale, and fund-raising and management in a wealthy one. His ability determines the efficiency with which he carries these tasks out.

The organization receives income only from donations. Its founder splits that income between development aid, wages to the worker, and perks (or profits, in the case of a FP) to herself. As altruistic workers receive utility from their involvement in development work, they may be paid a lower wage than selfish workers for a given level of such work.

A representative donor imperfectly observes the organization's records. Thus, he may not observe the types of either the founder (i.e. altruistic or selfish) or the worker (again, altruistic or selfish, but now also high ability or low ability). Neither, as he is not 'in the field', may he observe the actual level of development work done. Finally, as he does not observe the founder's personal behaviour, he cannot observe the perks that she takes from the organization, though he can observe the organization's type - that is, whether it is a for profit or a not-for-profit firm.

Therefore, this is a model of 'small' donors - the charitably-inclined public: in reality, large institutional donors may be able to insist on more detailed information about the agency's activities. Small donors cannot bargain with the agency but have to accept the signal that the agency chooses to provide.

Thus, donors may only observe the worker's wages. If they also observe the worker's type, they can infer from the wages of an altruistic worker what level of development work the organization undertakes. However, if types are not observable, donors may be unable to infer the level of development work from the wage. For instance, a comparatively low wage might indicate that a high ability worker is willing to work for a wage well below his outside option because of the high level of development work the organization is doing. Alternatively, it might indicate that the worker is of low ability and the organization is doing only moderate levels of development work.

In Section 2 we present a model with pure moral hazard: the founder 
is observed to be either purely selfish, or to have an altruistic motive as well. The founder's actions, however, may not be observable. We thus consider the employment of altruistic workers purely as a commitment device against moral hazard. We show that in these circumstances there is no role for incorporation as a not-for-profit firm as a commitment mechanism: it is true that, when founded by altrusitic founders, not-for-profit firms undertake higher levels of development work than do for-profit firms, but the cost of the signal is too high given that there is an alternative signal available in the form of the wage. Section 3 introduces adverse selection, in which neither founders' nor worker's types are observable in equilibrium - we consider the incentive constraints that must be satisfied in a separating to occur in equilibrium. The double character of the adverse selection problem makes it difficult to find analytic solutions with full generality, because of countervailing incentives: in Section 4 we solve for particular specifications of the utility and cost functions, finding conditions for separating equilibria to exist, and showing the relative roles of signalling via wages and signalling via not-for-profit status. Finally, Section 5 concludes.

\section{The model with pure model hazard}

The model considers three agents, a donor, a founder and a worker. The founder moves first, making a wage offer to a single worker from a competitive labour market to carry out the work of an ostensibly charitable organization, which may be established either as a profit or as a not-for-profit firm. The donor, who moves last after observing the worker's wage and the organization's form, is the organization's sole source of funding.

The donor is endowed with a single unit of wealth. In addition to caring about his own consumption, he is altruistically motivated. Thus, his objective function is

$$
u_{D}=g(1-d)+h(d \cdot t)
$$

where $d \in[0,1]$ is the donation and $t$ is the fraction of $d$ spent on development work by the organization. Thus, the donor's altruism is 'results oriented'. The functions $g(\cdot)$ and $h(\cdot)$ satisfy:

$$
\begin{aligned}
g(0)=h(0) & =0 ; \\
g^{\prime}(0)=h^{\prime}(0) & =\infty ; \\
g^{\prime}(x), h^{\prime}(x) & >0 \forall x \in[0,1] ; \\
g^{\prime \prime}(x), h^{\prime \prime}(x) & <0 \forall x \in[0,1] .
\end{aligned}
$$


The founder is either motivated in the same way that the donor is, or is purely selfishly motivated. Both possibilities are incorporated in the general objective function,

$$
u_{F}=g(f \cdot k)+\alpha_{F} h(d \cdot t) ;
$$

where $f$ indicates the organization's form (i.e. for profit or non-profit), $k$ are the organization's profits and $\alpha_{F} \in\{0,1\}$ indexes the founder's level of altruism. In this section, we assume that $\alpha_{F}$ is common knowledge, though in the following section we shall relax this assumption.

Our altruistic founders therefore correspond to the default case in Glaeser and Shleifer (2001). Their founders care not only about profits but also about the (expensive) quality of their products.

The founder makes two types of decisions: those observable by the donor, and those hidden from him. In the first category are the form of her organization and the wage that she pays her worker. In the latter is $t$, the share of donations spent upon development work. In the model of pure moral hazard presented in this section, we assume that the worker's characteristics are observed by the donor.

The choice of organizational form, $f \in\{\rho, 1\}$, determines the efficiency with which the organization's profits can be transformed into income for the founder. Founding an FP is equivalent to setting $f=1$ while founding a NP sets $f=\rho \in(0,1)$, with $\rho$ a parameter determined outside the model by the rigour of the regulation of the NP sector.

The worker is capable of purely selfish $\left(\alpha_{W}=0\right)$ or altruistic $\left(\alpha_{W}=1\right)$ motivation, but may also be either high ability $(\theta=0)$ or low ability $(\theta=1)$. High ability workers implement projects and raise and manage funds more efficiently. In the model of pure moral hazard presented in this section, both $\alpha_{W}$ and $\theta$ are observed by the donor.

To simplify exposition, we assume that the altruistic component of her objective function is a function of $t$ and not of $d . t$, as follows:

$$
u_{W}=g(w)+\alpha_{W} h(t)
$$

where $w$ is her worker's wage. Technically, this simplifies calculations by removing the solution to the donor's problem, $d$, from the worker's. ${ }^{3}$ Economically, an altruistic worker is not motivated by results but by 'purity', the total proportion of its donations directed towards development. As the agent responsible for implementing the organization's work, she observes the transfer share set by the founder.

\footnotetext{
${ }^{3}$ Making the worker's altruism utility a function of both $d$ and $t$ adds technical complications without changing qualitative results.
} 
As the worker is hired from a competitive labour market, and as her type is observed by the donor, her wage leaves her no rents. When the worker is selfish, her wage is forced down to her outside option. These satisfy $1>\bar{w}>\underline{w}>0$, with the high ability worker's outside wage exceeding the low ability's. The upper bound ensures that it is feasible to hire a selfish, high ability worker under the most permissive conditions (i.e. when $d=1$ ).

When the worker is altruistic, she will be driven below her outside wage option by an organization setting $t>0$, thereby paying her in altruism utility. Therefore:

$$
w\left(\alpha_{W}, \theta, t\right)=\left\{\begin{array}{ll}
\underline{w} & \text { if } \alpha_{W}=0, \theta=1 \\
\bar{w} & \text { if } \alpha_{W}=0, \theta=0 \\
\max \left\{0, g^{-1}(g(\underline{w})-h(t))\right\} & \text { if } \alpha_{W}=1, \theta=1 \\
\max \left\{0, g^{-1}(g(\bar{w})-h(t))\right\} & \text { if } \alpha_{W}=1, \theta=0
\end{array}\right\} .
$$

Thus, for sufficiently high levels of $t$, the worker could earn rents even by working for free. We would not normally expect to see this occur in equilibrium as the Inada conditions on consumption utility make it prohibitively expensive for the founder to hold the worker to a zero wage (except in the extreme case where $\rho$ is close to zero) .

From the assumptions on the utility function it follows straightforwardly that for every $t \in[0,1]$,

$$
w(0,0, t) \geq w(1,0, t)>w(1,1, t) .
$$

Thus, competitive wages display both ability premia and altruism discounts.

\subsection{The donor's problem}

The donor maximises equation 1 by choice of $d \in[0,1]$. As his objective function depends on the transfer set by the founder, he seeks to infer $t$ even though he cannot observe it directly. Observing the worker's type makes this straightforward: as the terms in wage equation 8 are invertible, observing the wage allows $t$ to be inferred.

The following lemmas establish conditions for $d(t)$ to be well-behaved that is, an increasing concave function of $t$.

Lemma 1. In an equilibrium of the pure moral hazard model, donations are positive if and only if the transfer, $t$, is as well.

The proof is in Appendix A. Intuitively, if the founder makes no transfer, no donation yields the donor any altruism utility. As the donor's marginal 
utility of altruism is infinite at this point, so will be his marginal donation. This helps ensure an interior solution in donations, something also proven in the appendix.

In what follows, we assume that the coefficient of relative risk aversion in altruism be bounded below unity:

$$
-x \frac{h^{\prime \prime}(x)}{h^{\prime}(x)}<1 \forall x \in[0,1] .
$$

Lemma 2. Inequality 10 is a necessary and sufficient condition for donations to increase over $t \in[0,1]$.

Again, the proof is relegated to Appendix A. The condition is intuitive: it states that the donor's marginal utility of altruism must not decrease so fast that the income effect outweighs the substitution effect of increases in $t$. If it did, increases in $t$ would cause the donor's marginal utility of altruism to fall to an extent that led the donor to wish to take more of his utility through consumption, thus reducing $d$. In what follows we assume that this upper bound on relative risk aversion holds. Thus, the maximum donation occurs when $t=1$. Denote this by $\bar{d} .^{4}$

When inequality 10 holds with equality, the donations function is linear.

\subsection{The founder's problem}

The founder maximises equation 6 subject to the budget constraint

$$
d=k+w+d \cdot t+c(\theta(1+t) d)
$$

where $c(\cdot)$ indicates management costs. ${ }^{5}$ These depend on two elements: the worker's ability and the volume of work to be performed by her. This, in turn, has two components: raising and managing the donation, $d$, and then implementing the development project, $d \cdot t$. These two tasks are treated symmetrically, so that the volume of work is their sum, $(1+t) d$.

\footnotetext{
${ }^{4}$ Implicitly, $\bar{d}$ is defined by $g^{\prime}(1-\bar{d})=h^{\prime}(\bar{d})$.

${ }^{5}$ Strictly speaking these are 'wastage costs' - costs over and above the efficient minimum costs necessary to manage a portfolio of a given size. This is because we normalise the cost function to zero for a high-ability worker. The net cost of the worker to the firm is not invariant between worker types (that is, the wage does not adjust to their differential productivity) because of the assumption that wages are set in a competitive labor market - thus, relative wages are determined by relative outside options, not by relative productivities within the firm.
} 
For simplicity, assume that the $\theta=0$ (high ability) worker, induces no management costs. Otherwise, they are convex and increasing in their arguments. Thus, the management cost function satisfies:

$$
\begin{aligned}
c & \in \mathcal{C}^{2} ; \\
c(0) & =0 ; \\
c^{\prime}(0) & =0 ; \\
c^{\prime \prime}(x) & >0 \forall x \in[0,1] ; \text { and } \\
c^{\prime}(2) & \leq 1 .
\end{aligned}
$$

The final inequality bears explanation. We wish to assume that costs never rise so quickly that a larger donation could leave a founder worse off. Thus, we wish the marginal management cost of donations to be less than unity; with convex costs, this need only hold at their maximal argument, $(1+t) d$. Thus, imposing it at 2 is conservative but avoids conditions on endogenous variables.

Finally, we assume that low ability workers cost enough to matter to founders but not so much that they would not be employed even by an organization undertaking no development work. That is, for high enough donation and development levels an low ability worker will cost the founder more in wastage than he saves her in wage costs, but for a firm receiving only donations and undertaking no development, low ability workers are better value.

$$
c(2 \bar{d})>w(1,0,1)-w(1,1,1)>c(\bar{d})
$$

Were this not the case, low ability altruistic workers would be cheaper than high ability altruists, or vice versa, for all levels of $t \in[0,1]$.

Substituting budget constraint 11, wage function 8 and donation function 29 into objective function 6 yields the founder's maximand:

$$
u_{F}=g\left(f\left[(1-t) d-c(\theta(1+t) d)-w\left(\alpha_{W}, \theta, t\right)\right]\right)+\alpha_{F} h(d \cdot t) .
$$

Unfortunately, this is not in general concave in the transfer share. While the primitives $g(\cdot), h(\cdot)$ and $-c(\cdot)$, are all concave, their combination may not be. Intuitively, the founder's choice of $t$ not only has a direct effect on her utility but also two or three indirect effects. Directly, higher $t$ leaves the founder a smaller share of the donation pie to consume herself - a negative effect. The first indirect effect is in donations: higher $t$ induces more donations - a positive effect. The second is a wage effect: higher $t$ allows altruistic workers to be retained at a lower wage, also a positive effect. The combination of these two positive effects may violate concavity. The third indirect effect is only experienced by employers of low ability workers: increased $t$, and 
the consequent increase in donations $d(t)$, induce more management costs, a negative effect. Finally, when founders are altruistic, there is a fourth utility effect of changes in $t$ : a direct, positive altruism effect. They experience a direct utility gain from increases in the proportion of their budget spent on development.

However, even without establishing concavity we can still show a number of results that must hold at any maximum. First, we show a simple relation between the share of transfers chosen by the founder and the employment decision:

Lemma 3. There is a unique share of transfers, $\tau$, such that, if the equilibrium transfer share exceeds $\tau$ it involves a high ability, altruistic worker; otherwise, an low ability, altruistic worker is used.

See Appendix A for the proof. Again, the intuition is straightforward. When little development work is undertaken, the high ability worker's higher base wage, $\bar{w}$, outweighs her management cost savings. Thus, it is more efficient to hire an low ability worker. The same argument holds in reverse for high levels of development work. Finally, only altruists are hired as they reduce the wage bill without adding costs for all positive $t$.

We now present results on the transfers undertaken by selfish and altruistic founders.

Lemma 4. In an equilibrium of the pure moral hazard model, an altruistic founder sets a higher transfer share than does a selfish founder. In both cases, the share lies strictly between zero and one.

The proof (in Appendix A) has a simple intuition. At whatever transfer share solves the selfish founder's problem, say $t_{0}^{*}$, the altruistic founder still experiences positive marginal utility to transfers. Thus, she will increase her transfer to $t_{1}^{*}$.

The transfer shares are interior as, at the extremes, the Inada conditions are encountered: at $t=0$, no donations are received; at $t=1$, maximal donations are received, but nothing is left for consumption utility. Thus, profits, $k$, are also interior in equilibrium.

Theorem 1. In an equilibrium of the pure moral hazard model, the transfer share set by a selfish founder, $t_{0}^{*}$, is independent of the organizational form of the agency.

This may be seen by inspecting maximand 14 . When $\alpha_{F}=0$, the founder maximises the argument of the square bracketed term. This is independent of $f$. 
This is not the case for altruistic founders. As in Glaeser and Shleifer (2001), the founder's choice of organizational form matters: $f$ does not cancel out of the first order conditions.

Theorem 2. When the coefficient of relative risk aversion in money is bounded below unity, so that

$$
-x \frac{g^{\prime \prime}(x)}{g^{\prime}(x)}<1 \forall x \in[0,1]
$$

altruistic founders of non-profits decrease $t_{1}^{*}$ as $\rho$ increases.

This result seems intuitive: more stringent regulatory requirements on NPs induce their founders to spend a higher share of donations on development aid, provided once again that the income effect does not outweigh the substitution effect (which would occur if the utility function were too concave in consumption). This is because such regulatory requirements raise the cost of using donations for perks relative to using them for development.

When Theorem 2 holds, an altruistic founder sets a lower $t$, thereby inducing a lower $d$, when she founds a FP than when she founds an NP. Nevertheless, she prefers to optimise with $f=1$ than with $f=\rho<1$. This result is unsurprising given that her altruism is observable: as the worker's wage is doing all the signalling required, further signalling with organizational form choice is unnecessary.

As this argument also holds for selfish founders, we may conclude:

Theorem 3. If a founder's altruism is observable, no founder incorporates as an a non-profit.

Similarly, full information rules out advertising in Milgrom and Roberts (1986). However, as we shall see below, the choice of organizational form may indeed matter for signalling when the founder's altruism is not observable. We consider this now.

In Glaeser and Shleifer (2001) the only type of founder corresponded to our altruistic, given her concern for quality. However, they did not allow signalling by wages. Thus, in their environment, signalling with organizational form is relevant. In our case, with observable wages, founders find them to be cheaper signals.

\section{Adding adverse selection}

In this section, we add an adverse selection problem to the donor's problem. Now, he cannot observe either the founder's type or the worker's ability 
level. ${ }^{6}$ The problem is now a 'general principal-agent problem' (Myerson, 1982), combining adverse selection with moral hazard.

As previously, the founder's choice of organizational form, $f$, and wage, $w$, are observable to the donor, while the transfer share, $t$, is not. Now, however, the donor cannot observe types either. Thus, he does not initially know the founder's altruism, $\alpha_{F}$, the worker's, $\alpha_{W}$, or the worker's ability, $\theta$.

The donor again waits for the founder's decisions before setting $d .^{7}$

We look for Perfect Bayesian equilibria. ${ }^{8}$ We denote the equilibrium choices of a selfish founder by a 0 subscript and those of an altruistic one by a 1 subscript. If $f_{0} \neq f_{1}$, we say that the equilibrium displays organizational separation. If $w_{0} \equiv w\left(\alpha_{F 0}, \theta_{0}, t_{0}\right) \neq w_{1} \equiv w\left(\alpha_{F 1}, \theta_{1}, t_{1}\right)$, we say that the equilibrium displays wage separation. While the former generally implies the latter, the converse is not true.

As we focus on separating equilibria, we need only consider pure strategies: if more than one action were in the support of a separating equilibrium, which earned the founder some donation, she would only ever take the least cost action.

As usual, analysis proceeds by writing incentive compatibility (IC) constraints for both founder types. A separating equilibrium arises if both founder types derive higher utility from honest behaviour than they do from fraud. As the donor knows neither the founder's nor the worker's type, there are three forms of fraud to consider:

1. pure $\theta$-fraud, whereby the donor mistakenly infers the worker's type (but not the founder's). Denote the unobservable transfer shares and worker types hired by a tilde.

2. pure $\alpha$-fraud, whereby the donor mistakenly infers the founder's type (but not the worker's.).

3. $\alpha \theta$-fraud, whereby the donor mistakenly infers both types. Denote the unobservable transfer shares and worker types hired by a caret.

Not knowing the worker's type ex ante prevents the donor, upon observing a wage, inverting the relevant wage schedule to retrieve the transfer share, $t$.

\footnotetext{
${ }^{6}$ Only altruistic workers will be hired: for any founder setting $t \geq 0$ they are weakly cheaper without any productivity or signalling disadvantages. When $t>0$, this is strictly so.

${ }^{7}$ If the problem were one of screening rather than signalling, the donor would initially set contracts, which the founders could take or leave (Armstrong and Rochet, 1999). Jullien, Salanié, and Salanié (2003) analysed the generalised agency case.

${ }^{8} \mathrm{With}$ two periods and two types, $\mathrm{PBE}$ is equivalent to sequential equilibrium.
} 
Instead, he must attempt to deduce both which wage schedule is the relevant one, and whether the worker is being held to her schedule.

Figure 1 illustrates the problem. The two decreasing functions represent the wage schedules for the high ability and low ability workers. The increasing function represents the management cost induced by an low ability worker. Thus, the thickened parts of the wage schedules reflect the efficient worker choice under pure moral hazard: a high ability worker is hired if and only if $t \geq \tau$. It may therefore be seen that there is a range of wages consistent with two transfer shares:

$$
w(1,1, \underline{t})=w(1,0, \bar{t})
$$

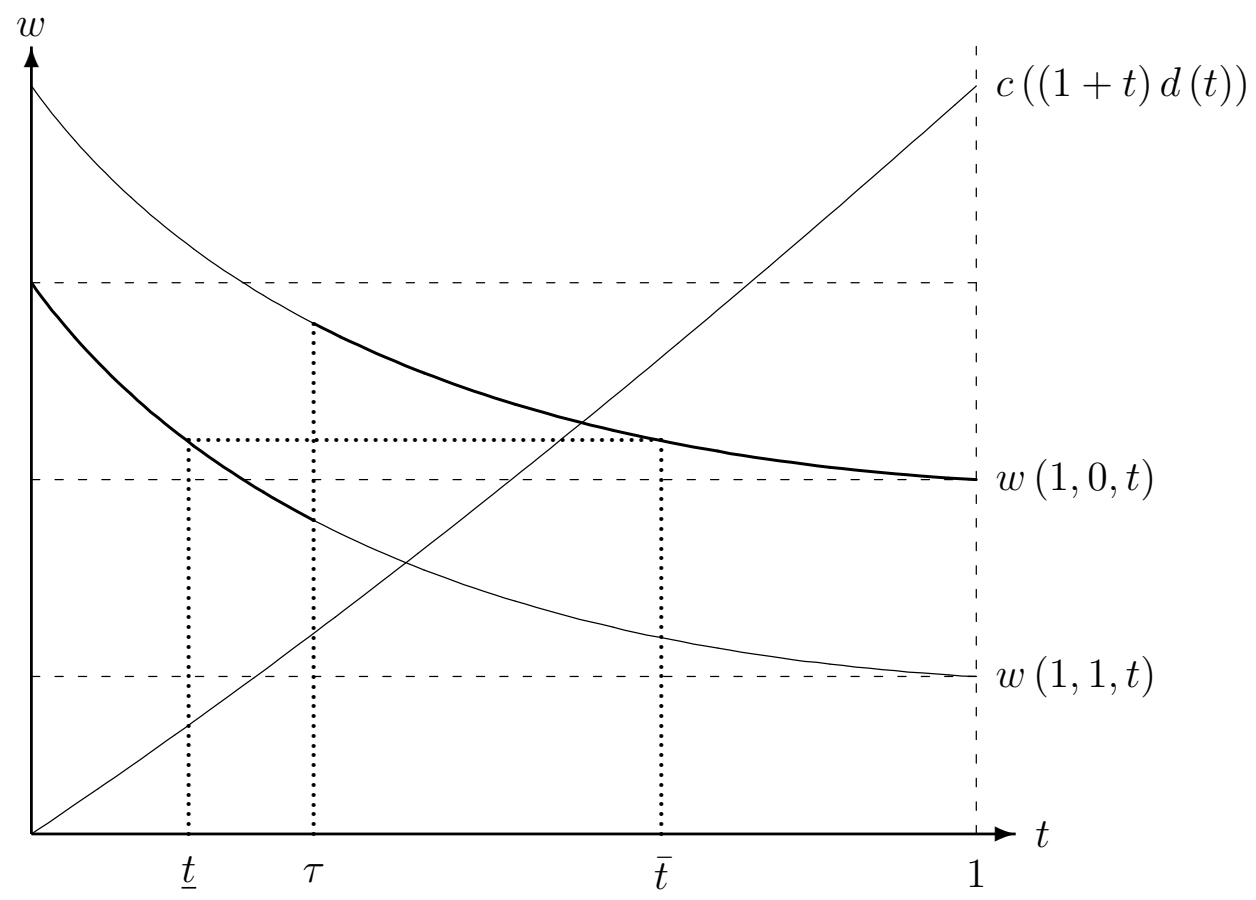

Figure 1: Multiple transfers consistent with a single wage

We now write the founders' IC and individual rationality constraints with 
maximal generality. The selfish founder's constraints are:

$$
\begin{aligned}
& f_{0}\left[\left(1-t_{0}\right) d\left(t^{e}\left(f_{0}, w_{0}\right)\right)-c\left(\theta_{0}\left(1+t_{0}\right) d\left(t^{e}\left(f_{0}, w_{0}\right)\right)\right)-w_{0}\right] \\
\geq \max & \left\{f_{0}\left[\left(1-\tilde{t}_{0}\right) d\left(t^{e}\left(f_{0}, w_{0}\right)\right)-c\left(\tilde{\theta}_{0}\left(1+\tilde{t}_{0}\right) d\left(t^{e}\left(f_{0}, w_{0}\right)\right)\right)-w_{0}\right]\right. \\
& f_{1}\left[\left(1-t_{1}\right) d\left(t^{e}\left(f_{1}, w_{1}\right)\right)-c\left(\theta_{1}\left(1+t_{1}\right) d\left(t^{e}\left(f_{1}, w_{1}\right)\right)\right)-w_{1}\right] \\
& f_{1}\left[\left(1-\hat{t}_{0}\right) d\left(t^{e}\left(f_{1}, w_{1}\right)\right)-c\left(\hat{\theta}_{0}\left(1+\hat{t}_{0}\right) d\left(t^{e}\left(f_{1}, w_{1}\right)\right)\right)-w_{1}\right] \\
& 0\}
\end{aligned}
$$

where $t^{e}(\cdot)$ indicates the transfer inferred by the donor on the basis of observable variables. The optimal deviations considered on the right hand side are pure $\theta$-fraud, pure $\alpha$-fraud and $\alpha \theta$-fraud, respectively. Inequality 21 is the IR constraint.

The altruistic founder's constraints are:

$$
\begin{aligned}
& g\left(f_{1}\left[\left(1-t_{1}\right) d\left(t^{e}\left(f_{1}, w_{1}\right)\right)-c\left(\theta_{1}\left(1+t_{1}\right) d\left(t^{e}\left(f_{1}, w_{1}\right)\right)\right)-w_{1}\right]\right)+h\left(d\left(t^{e}\left(f_{1}, w_{1}\right)\right) t_{1}\right) \\
\geq \max \left\{g\left(f_{1}\left[\left(1-\tilde{t}_{1}\right) d\left(t^{e}\left(f_{1}, w_{1}\right)\right)-c\left(\tilde{\theta}_{1}\left(1+\tilde{t}_{1}\right) d\left(t^{e}\left(f_{1}, w_{1}\right)\right)\right)-w_{1}\right]\right)+h\left(d\left(t^{e}\left(f_{1}, w_{1}\right)\right) \tilde{t}_{1}\right)\right. & (23) \\
& g\left(f_{0}\left[\left(1-t_{0}\right) d\left(t^{e}\left(f_{0}, w_{0}\right)\right)-c\left(\theta_{0}\left(1+t_{0}\right) d\left(t^{e}\left(f_{0}, w_{0}\right)\right)\right)-w_{0}\right]\right)+h\left(d\left(t^{e}\left(f_{0}, w_{0}\right)\right) t_{0}\right), \\
& g\left(f_{0}\left[\left(1-\hat{t}_{1}\right) d\left(t^{e}\left(f_{0}, w_{0}\right)\right)-c\left(\hat{\theta}_{1}\left(1+\hat{t}_{1}\right) d\left(t^{e}\left(f_{0}, w_{0}\right)\right)\right)-w_{0}\right]\right)+h\left(d\left(t^{e}\left(f_{0}, w_{0}\right)\right) \hat{t}_{1}\right),
\end{aligned}
$$

$$
0\} \text {. }
$$

Thus, neither founder may 'half-misrepresent' her type by adopting only some of the other founder's observable choices. Doing so would not disguise herself as the other type but would, instead, reveal to the donor that she is engaged in fraud.

At this stage, analysis typically invokes sufficient conditions for single crossing to simplify the nonlinear programming problem. The standard sufficiency condition for single crossing with discrete types is that

$$
u_{F}(f, w, d(t(\cdot)), 1, \theta(\cdot), t(\cdot))-u_{F}(f, w, d(t(\cdot)), 0, \theta(\cdot), t(\cdot)) ;
$$

be monotone in $w$, where the unobserved $t(\cdot)$ and $\theta(\cdot)$ are functions of founder type and the observed actions, $\left(\alpha_{F}, f, w\right){ }^{9}$

\footnotetext{
${ }^{9}$ Technically, it should also be monotonic in $f$, but this is automatic as $f \in\{\rho, 1\}$.
} 
We have been unable to show that such a condition generally holds in this model. Intuitively, the difficulty arises because the founders' hidden information on type and action give them 'countervailing incentives', reasons to represent themselves both as more and as less altruistic than they actually are. A selfish founder has an incentive to encourage the donor to believe her altruistic, and thus believe her to be setting a higher transfer share. Similarly, an altruistic founder may have an incentive to encourage the donor to believe her selfish, and thus believe that a large donation is necessary to induce development spending. While the two types of founder differ only in their degree of altruism, the possibility that their different hidden types may lead them to have different hidden actions (whether the type of worker they employ, or the transfers that they set) means that single-crossing may no longer obtain: variations in $w$ may, for example, induce discrete variations in $\theta$ for any given $\alpha_{F} \cdot{ }^{10}$

Without single crossing, analytical results are uncommon. We may still make some progress analytically by eliminating cases of $\theta$-fraud in some circumstances.

Lemma 5. Neither founder type will be tempted to commit pure $\theta$-fraud by setting a transfer share above the donor's expectation.

The proof, in Appendix A, has a straightforward intuition. Whatever transfer share the founder sets, sending a signal that leads donors to underestimate this share would yield not benefit but would be costly for two reasons: it would earn her lower donations, and it might require her to make higher wage payments. It follows from the lemma that pure $\theta$-fraud can only pose a threat to separation when an honest founder hires a high ability worker. Otherwise, if such a founder hires an low ability worker, deviation to a lower $t$ becomes impossible without altering the wage.

The same argument allows us to establish that:

Lemma 6. Neither founder will be tempted to commit $\alpha \theta$-fraud by setting a transfer share above that implied by the corresponding pure $\alpha$-fraud.

The proof, in Appendix A, has the same intuition as its predecessor.

The above lemmata may reduce the forms of fraud against which a candidate separating equilibrium must guard. Table 1 displays the possibilities, arranged by the worker types hired by honest founders. As these still seem insufficient to establish single crossing, we now confine our analysis to a particular class of models.

\footnotetext{
${ }^{10}$ Maggi and Rodríquez-Clare (1995) claim that general results do not exist for screening games with countervailing incentives. We are not aware of general results for signalling games.
} 


\begin{tabular}{cl|l|l|} 
& \multicolumn{2}{|c}{ selfish founder's choice } \\
& high ability & low ability \\
\cline { 2 - 4 } altruist's choice & high ability & selfish: all & selfish: $\alpha, \alpha \theta$ \\
& altruist: all & altruist: $\alpha, \theta$ \\
\cline { 2 - 4 } & low ability & selfish: $\alpha, \theta$ & selfish: $\alpha$ \\
& altruist: $\alpha, \alpha \theta$ & altruist: $\alpha$ \\
\hline
\end{tabular}

Table 1: Potential fraud types by candidate separating equilibrium

\section{A model with quadratic management costs}

In this section we study a special case in which

$$
g(x)=h(x)=2 \sqrt{x} .
$$

These specific functional forms satisfy the conditions imposed above on utility functions. They also allow

$$
-x \frac{g^{\prime \prime}(x)}{g^{\prime}(x)}=-x \frac{h^{\prime \prime}(x)}{h^{\prime}(x)}=\frac{1}{2}<1 ;
$$

which, by Lemma 2, guarantees increasing donations. Further, the donation function reduces to

$$
d(t)=\frac{t}{1+t} .
$$

We also assume that

$$
\underline{w}=1 \text { and } \bar{w}=\frac{5}{4} .
$$

These ensure that wages remain positive over $t \in[0,1]$.

Finally, a full model also requires specification of the management costs. We assume that $c(x)=\gamma x^{2}$, where $\gamma$ is a positive constant. We investigate three instances of $\gamma$, a high cost scenario $\left(\gamma=\frac{1}{2}\right)$, a low cost scenario $\left(\gamma=\frac{1}{10}\right)$, and an intermediate cost scenario $\left(\gamma=\frac{1}{4}\right)$.

Full details of the solutions are given in Appendix B: we concentrate here on the key economic intuitions. When management costs are high, $\gamma=\frac{1}{2}$, we find a unique separating equilibrium. It exhibits wage separation: both founder types found FPs and hire high ability workers. Intuitively, the high management costs make both forms of $\theta$-fraud prohibitively expensive; pure $\alpha$-fraud is eliminated by the differences in the founders' objective functions. As all forms of fraud are eliminated, costly signals (like founding an NP, or hiring a low ability worker as proof against fraud) are unnecessary, and no founder establishes a non-profit. See Appendix B for a more detailed discussion. 
Similarly, when management costs are low, $\gamma=\frac{1}{10}$, we again find a unique separating equilibrium. It too exhibits wage separation: again, both founder types found FPs, but now they hire low ability workers. If, instead, they hired high ability workers, the low management costs would make $\theta$-fraud irresistible. Thus, only pure $\alpha$-fraud is left, and the difference in founders' objective functions makes this easy to overcome. Thus, costly signalling by incorporating as a NP is not necessary, but founders hire low ability workers as a commitment device against $\theta$-fraud.

As founders only establish FPs in these cases, equilibria are insensitive to the stringency of NP regulation, $\rho$. Thus, no issues arise for policy makers in deciding how stringently to regulate NPs. When management costs are intermediate, $\gamma=\frac{1}{4}$, there are separating equilibria which do involve organizational separation. Thus, policy questions do arise. Further, the equilibrium choices vary in $\rho$.
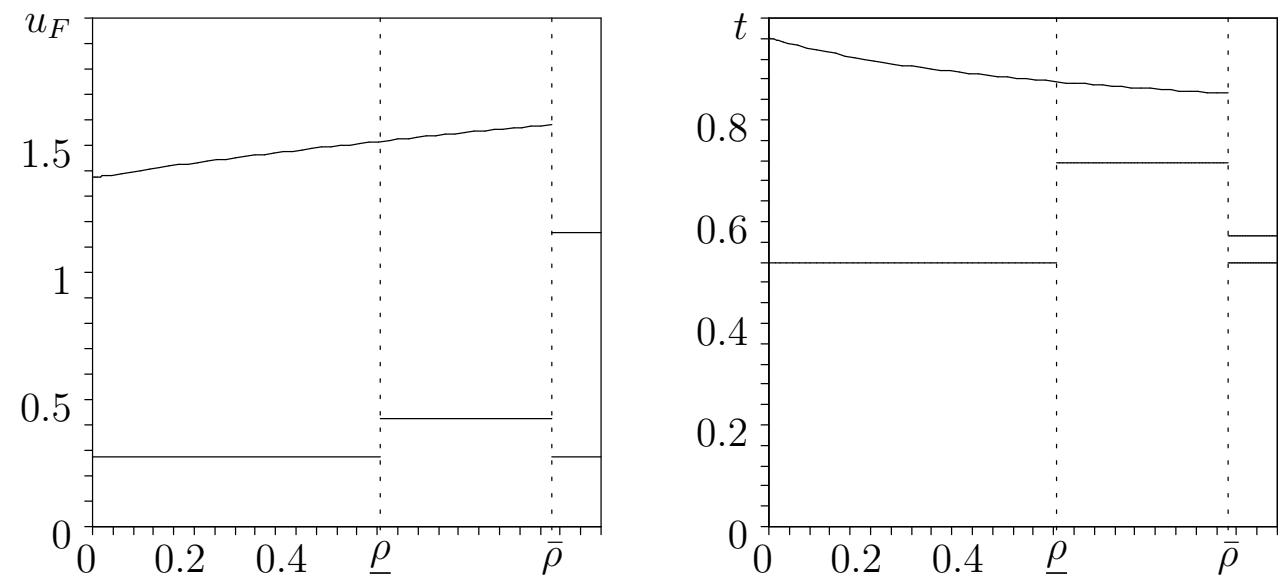

Figure 2: Founders' utility and transfer shares when $c(x)=\frac{1}{4} x^{2}$

The left panel of Figure 2 depicts founders' equilibrium utility as a function of NP regulatory stringency. Its upper curve corresponds to altruists, the lower to selfish founders. The dashed vertical lines at $\rho \approx 0.57$ and $\bar{\rho} \approx 0.90$ divide the diagram into three equilibrium regimes. The Figure's right panel depicts equilibrium transfer shares.

The rightmost region corresponds to loose NP regulation, thus $\rho>\bar{\rho}$. In this, both types found FPs and hire low ability workers. Thus, this too is a case of wage separation. Organizational separation does not occur as NP regulation is not yet sufficiently stringent for the signal to be meaningful. This, in turn, leads both founders to set relatively low transfer shares (see the 
right panel of Figure 2) and hire low ability workers: a founder who wished to hire high ability workers to efficiently manage large transfers would find $\theta$-fraud too tempting.

Now consider the middle region of the Figure, corresponding to more stringent NP regulation, in which $\rho \in[\rho, \bar{\rho}]$. In this, the altruist founds a NP while the selfish founder establishes a FP. Thus, there is now organizational separation. Perhaps surprisingly, both hire high ability workers. For the altruist, more stringent regulation increases the relative merits of development work, and thus the value of the high ability worker. For the selfish founder, her transfer share is sufficiently high that the high ability worker is more efficient.

Finally, consider the leftmost region, corresponding to very stringent NP regulation, $\rho<\rho$. The altruistic founder continues to run a NP with a high ability worker. While the selfish founder continues to establish a FP, she reverts to employing a low ability worker. She sets the same transfer share, and earns the same utility as she did when $\rho>\bar{\rho}$.

Under stringent regulation, it is clearly onerous to run a NP instead of a FP. If, however, the altruistic founder were to found a FP she would succumb to pure $\theta$-fraud, and try to pass a low ability worker off as high ability. Even founding a FP and honestly hiring a low ability worker would reduce her utility.

Thus, as $\rho \rightarrow 0$, and the returns to consumption fall, the altruistic founder continues to raise the transfer share. In the limit, she is able to set $t$ close to one: she consumes nothing herself, and $t$ is high enough to drive her worker's wage down; see the right panel of Figure 2.

When the costs associated with low ability workers are intermediate, therefore, policy makers can alter behaviour by choice of regulatory regime. Figure 3 depicts total equilibrium transfers, $t \cdot d(t)$, as a function of $\rho$. For the selfish founder, both highly stringent and lax regulatory regimes lead to the same overall transfers. As the founder hires low ability workers in these cases, these are lower than the overall transfers in the intermediate regime, with the high ability worker.

Once the regulatory regime is sufficiently strict for the altruistic founder to establish a NP, her overall transfers continue to rise as the regime becomes stricter.

Thus, a policy maker interested in maximising overall transfers must assess the likelihood of the unknown founder being altruistic relative to her being selfish. If the policy maker thinks that altruists dominate, a very strict regime is called for. On the other hand, if the policy maker thinks that selfish founders are more likely, setting $\rho$ just above $\rho$ is optimal: it induces maximal transfers from the (expected) selfish founder $\bar{b}$ ut, should the founder turn out 


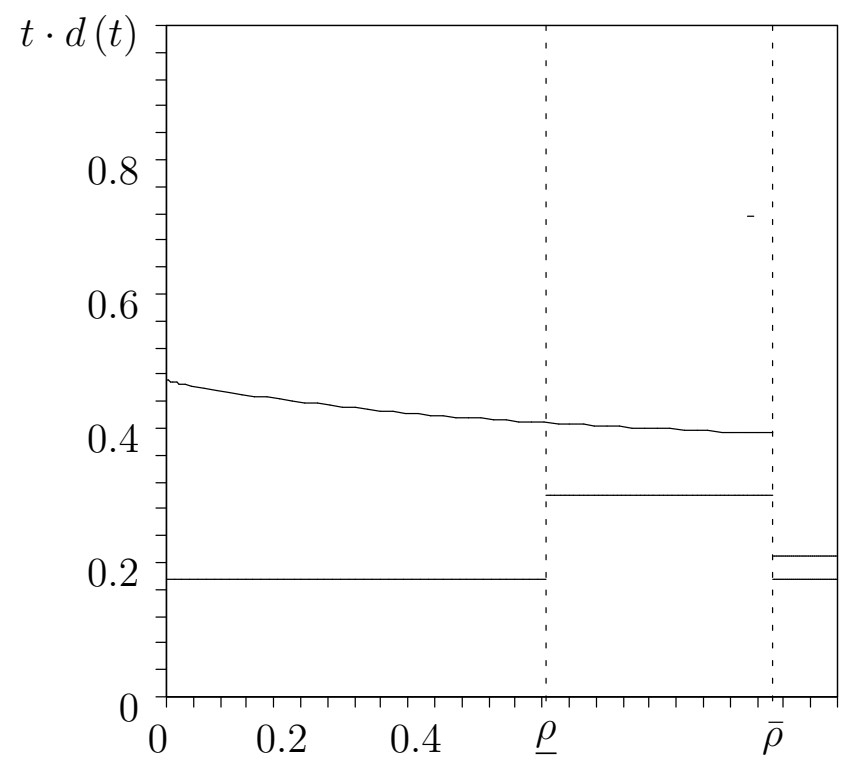

Figure 3: Total transfers when $c(x)=\frac{1}{4} x^{2}$

to be altruistic, still induces higher transfers than a more lax regime would.

\section{Conclusions}

In this paper we explore the idea that charitable organizations act like banks to transfer funds between providers of funds and those who have worthwhile projects that need funds. However, unlike banks, charities cannot signal to donors the quality of the projects they fund by providing a financial return. Instead, they can use the salary paid to employees (or other indicators such as spending on overheads) as a signal to donors of the quality of the work that employees undertake, where quality is understood in terms of the overall proportion of the organization's portfolio that is directed to development projects. An employee would accept a job at a lower wage than that available in the outside labor market only if the job afforded genuine altruistic compensation. The donor can then infer that the organization is doing genuinely good work. Furthermore, when founders are altruistic, the quality of the work done will be higher in a NP firm than in a FP.

It is important to note, however, that in this model, establishing a not-forprofit organization is of no value purely for solving moral hazard problems. It is true that, provided founders are altruistic, they undertake higher levels of 
development work under not-for-profit status. However, the cost to them of such status outweighs the pure commitment value. Where NP status really comes into its own, however, is in solving the adverse selection problem associated with founder and worker types. In a world in which founders cannot all be assumed to be altruistic and in which it may be hard to know the ability of workers in advance, this seems to us to be an important consideration.

The adverse selection problem is as follows: inferring the quality of the work done by the organization from the wage offered to its employees may be possible only if the ability of the employees is known - a given low wage may result from a high ability worker and high quality work, or a low ability worker and low quality work. The donor also needs to be sure, in order to infer the quality of the work done from the salary, that he has correctly inferred the founder's type (where this is not directly observable). We have shown that the nature of the equilibria in which such inferences are possible depends on two things: the costs associated with employing low-ability workers, and the strictness of regulation of not-for-profit firms. When the costs of low-ability workers are either very low or very high, both types of founders hire the same type of worker, and donors can simply infer the work of the organization from the wage without fear of misrepresentation in equilibrium. Consequently there is no need for founders to engage in the costly signal of incorporating as a not-for-profit firm. However, intermediate costs make misrepresentation of worker type a more realistic concern, and at this point incorporation as a not-for-profit becomes a valuable signal for altruistic founders. However, the nature of the equilibrium depends on the strictness of NP regulation. When NP regulation is loose, founders cannot meaningfully signal by incorporating as NPs. Thus, the separating equilibrium for high values of $\rho$ displays wage rather than organizational separation. Further, the ease with which $\theta$-fraud could be committed were they to hire high ability workers forces them, in equilibrium, to hire low ability workers. As NP regulation becomes stricter, organizational separation becomes meaningful, and is taken advantage of by altruistic founders, who found NPs. Doing so further induces them to hire high ability workers, thus aiming to derive their utility from good works rather than perks. When NP regulation is of intermediate strictness, the selfish founder also hires a high ability worker. Were she to do this when NP regulation was very strict, however, the altruistic founder would prefer to pretend to be selfish; thus, under very strict regulation, the selfish founder reverts to hiring an low ability worker.

Our approach to the signalling problem is nevertheless fairly special: we assume, to simplify the problem, that donors have no other ways to discover whether founders have misled them. In reality, of course, other instruments are available, including audits, press and media coverage, and direct involve- 
ment on the part of donors. Unless such monitoring instruments work perfectly there may still be a role for the kind of signalling mechanism we have described, but the interaction of monitoring and signalling will be subtle. Including such monitoring instruments into a more complete model of agency behaviour is an interesting challenge for future work.

\section{A Proofs}

Proof of Lemma 1. Differentiating the objective function implicitly defines a unique maximum for all $t \in[0,1]$ :

$$
g^{\prime}(1-d)-h^{\prime}(d \cdot t) t=0 .
$$

When $t=0$, the unique solution is $d(0)=0$ : the monotonicity of $g(\cdot)$ prevents an interior $d$ from solving $g^{\prime}(1-d)=0$.

When $t>0$, this has a unique solution in $d \in(0,1)$ : the utility function is continuously differentiable, yielding infinite marginal utility in consumption at $d=1$ and in altruism at $d=0$. Uniqueness follows from the monotonicity of $g(\cdot)$ and $h(\cdot)$ and their opposing arguments.

Finally, implicit differentiation of equation 29 yields

$$
d^{\prime}(t)=-\frac{h^{\prime \prime}(d \cdot t) d \cdot t+h^{\prime}(d \cdot t)}{h^{\prime \prime}(d \cdot t) t^{2}+g^{\prime \prime}(1-d)} .
$$

At $t=0$, this reduces to $-\frac{h^{\prime}(0)}{g^{\prime \prime}(1)}=\infty$.

Proof of Lemma 2. As the denominator of equation 30 is negative, a positive sign overall depends on a positive numerator. The condition is equivalent to this.

Proof of Lemma 3. Proving the lemma reduces to proving that

$$
\delta(t) \equiv c((1+t) d)-(w(1,0, t)-w(1,1, t)) ;
$$

has a single root in $t \in[0,1]$. By equation 9 and $c(0)=0, \delta(0)=\underline{w}-\bar{w}<0$. By assumption 13, $\delta(1)>0$. As $c^{\prime}(\cdot)>0$, it suffices that $w(1,0, t)-w(1,1, t)$ be (weakly) monotonically decreasing in $t$.

When $t$ is high enough that $w(1,0, t)=w(1,1, t)=0$, this holds. When only $w(1,1, t)=0$ this also holds as $w(1,0, t)$ is declining towards zero.

Finally, when both $w(1,0, t)$ and $w(1,1, t)$ are positive, differentiation yields

$$
\delta^{\prime}(t)=h^{\prime}(t)\left[\frac{1}{g^{\prime}(g(\bar{w})-h(t))}-\frac{1}{g^{\prime}(g(\underline{w})-h(t))}\right] .
$$


When the bracketed term containing the fractions is positive, the result follows. This is now established:

$$
\bar{w}>\underline{w} \Rightarrow 0<g^{\prime}(g(\bar{w})-h(t))<g^{\prime}(g(\underline{w})-h(t)) .
$$

The reciprocal of this final term yields the result.

Proof of Lemma 4. Suppose that the selfish founder's maximand is concave in $t$. It therefore has a unique maximum at $t_{0}^{*}$. This is necessarily positive as, otherwise, she receives no donation: the marginal donation and, thus, her marginal utility are infinite at $t=0$.

The altruistic founder's first order condition adds

$$
h^{\prime}(d \cdot t)\left[d^{\prime}(t)+d\right]
$$

to that of the selfish founder. As this is always positive, the altruist's marginal utility is positive at $t_{0}^{*}$. Under concavity, $t$ can only be reduced to zero by increasing to some $t_{1}^{*}>t_{0}^{*}$. Finally, as $t_{1}^{*}=1$ leaves $k=0$, marginal disutility of $t$ at that point is infinite. Thus, $t_{1}^{*}<1$.

Now consider situations in which the selfish founder's maximand is not concave. If there remains a unique local maximum, the argument above goes through. If there are multiple local maxima, index them, starting with the leftmost. There are as many local maxima for the altruistic founder as there are for the selfish: the addition of the increasing, concave function increases the value of $t$ at each stationary point; none of them are forced beyond $t=1$ due to the infinite disutility experienced by the founder there.

If the addition of the altruism function does not change which local maximum is the global maximum, then the result is established. If it does, then the new maximum cannot correspond to a stationary point with a lower index number: the altruistic objective function adds an increasing function to its selfish counterpart. This establishes the result.

Proof of Theorem 2. As $h(\cdot)$ is not a function of $f$, the envelope theorem only requires that we consider

$$
\begin{aligned}
\frac{\partial^{2} g(\cdot)}{\partial t \partial \rho}= & \left\{-d+(1-t) d^{\prime}(t)-c^{\prime}(\cdot)\left[d+(1+t) d^{\prime}(t)\right]+\frac{h^{\prime}(t)}{g^{\prime}(\cdot)}\right\} \\
& \times\left[g^{\prime}(\rho k)+g^{\prime \prime}(\rho k) \rho k\right] .
\end{aligned}
$$

which must be negative for the theorem to hold. In equilibrium, the first bracketed term is negative: this must offset the positive derivative in the $h$ function. The terms in the second bracket are positive and negative, respectively. The stated condition ensures increasing differences so that $t_{1}^{*}$ decreases in $\rho$ when $f=\rho$. 
Proof of Lemma 5. Consider a candidate separating equilibrium in which one of the founder types sets $(\bar{f}, \bar{t}, \bar{\theta})$. Let $(\bar{f}, \tilde{t}, \tilde{\theta})$ be an instance of pure $\theta$-fraud (so that $\tilde{\theta} \neq \bar{\theta}$ ) with upward deviation (so that $\tilde{t}>\bar{t}$ ). Finally, suppose that this deviation is preferable to honesty:

$$
\begin{aligned}
& g(\bar{f}[(1-\bar{t}) d(\bar{t})-c(\bar{\theta}(1+\bar{t}) d(\bar{t}))-w(1, \bar{\theta}, \bar{t})])+\alpha_{F} h(d(\bar{t}) \bar{t}) \\
\leq & g(\bar{f}[(1-\tilde{t}) d(\bar{t})-c(\tilde{\theta}(1+\tilde{t}) d(\bar{t}))-w(1, \bar{\theta}, \bar{t})])+\alpha_{F} h(d(\bar{t}) \tilde{t}) .
\end{aligned}
$$

If the founder set $\tilde{t}$ but, instead of engaging in $\theta$-fraud, honestly signalled wages, her utility would be:

$$
g(\bar{f}[(1-\tilde{t}) d(\tilde{t})-c(\tilde{\theta}(1+\tilde{t}) d(\tilde{t}))-w(1, \tilde{\theta}, \tilde{t})])+\alpha_{F} h(d(\tilde{t}) \tilde{t}) .
$$

As $d(\cdot)$ is an increasing function, the altruism utility in this expression cannot be less than that under $\theta$-fraud. By this same argument, the first term in the $g(\cdot)$ function is now greater as well. Further, the assumption that $c^{\prime}(2)<1$ ensures that additional administrative costs (if $\tilde{\theta}=1$ ) cannot outweigh additional donations. Finally, honest signalling lowers the wage bill.

Thus, if there is a profitable instance of $\theta$-fraud involving upward deviation to $\tilde{t}>\bar{t}$ it, in turn, is outperformed by honest signalling at $\tilde{t}$. Thus, both the candidate $\bar{t}$ and upward deviations involving pure $\theta$-fraud may be eliminated: the first does not maximise the honest founder's utility; the second produces a contradiction.

Proof of Lemma 6 . Consider honest behaviour, $\left(f_{0}, t_{0}, \theta_{0}\right)$ by a selfish founder that is outperformed by an upward deviation to $\left(f_{1}, \hat{t}_{0}, \hat{\theta}_{0}\right)$ where $\hat{\theta}_{0} \neq \theta_{1}$ and $\hat{t}_{0}>t_{1}$ :

$$
\begin{aligned}
& f_{0}\left[\left(1-t_{0}\right) d\left(t_{0}\right)-c\left(\theta_{0}\left(1+t_{0}\right) d\left(t_{0}\right)\right)-w\left(1, \theta_{0}, t_{0}\right)\right] \\
\leq & f_{1}\left[\left(1-\hat{t}_{0}\right) d\left(t_{1}\right)-c\left(\hat{\theta}_{0}\left(1+\hat{t}_{0}\right) d\left(t_{1}\right)\right)-w\left(1, \theta_{1}, t_{1}\right)\right] .
\end{aligned}
$$

Honest signalling with this transfer share would yield

$$
f_{1}\left[\left(1-\hat{t}_{0}\right) d\left(\hat{t}_{0}\right)-c\left(\hat{\theta}_{0}\left(1+\hat{t}_{0}\right) d\left(\hat{t}_{0}\right)\right)-w\left(1, \hat{\theta}_{0}, \hat{t}_{0}\right)\right]
$$

which, as in Lemma 5 , outperforms this form of $\alpha \theta$-fraud.

The same argument applies to altruistic founders. In their case, the honest behaviour is $\left(f_{1}, t_{1}, \theta_{1}\right)$ while the putatively superior upward deviation is to $\left(f_{0}, \hat{t}_{1}, \hat{\theta}_{1}\right)$ where $\hat{\theta}_{1} \neq \theta_{0}$ and $\hat{t}_{1}>t_{0}$. 


\section{B Quadratic management costs}

Before considering particular values of $\gamma$ we discuss the method for analysing these models. Analysis requires determination of founders' optimal honest behaviour, as well as their optimal deviations. One of the founders' choice variables, the transfer share, is continuous. The other two, organizational form and worker ability, are binary. Thus, founders first maximise by choice of transfer share, holding their binary choice variables constant. Then, they compare the maximised values for different combination of the binary variables. Nevertheless, not all optimal transfer shares depend on both of the binary variables.

For the reasons outlined in Theorem 1, the honest selfish founder's optimal transfer share is independent of organizational form; as it depends on the worker's ability, we write $t_{0}\left(\theta_{0}\right)$. The honest altruistic founder's optimal transfer share depends on both of these, so that $t_{1}\left(f_{1}, \theta_{1}\right)$.

The selfish founder's optimal transfer share under pure $\theta$-fraud satisfies equation 16. As shown in Table 1, the selfish founder only need guard against this when $\theta_{0}=0$. Thus, as the selfish founder seeks to minimise the transfer share, her optimal deviation is:

$$
\tilde{t}_{0}\left(t_{0}\right)=\max \left\{0, h^{-1}\left(h\left(t_{0}\right)+g(\underline{w})-g(\bar{w})\right)\right\} .
$$

Similarly, as shown in Table 1, the selfish founder only need guard against $\alpha \theta$-fraud when $\theta_{1}=0$. In these cases the optimal fraud sets:

$$
\hat{t}_{0}\left(f_{1}, \theta_{1}\right)=\max \left\{0, h^{-1}\left(h\left(t_{1}\left(f_{1}, \theta_{1}\right)\right)+g(\underline{w})-g(\bar{w})\right)\right\} .
$$

Now consider the altruistic founder's optimal pure $\theta$-fraud. Again, as shown in Table 1 , this is only a threat when $\theta_{1}=0$. Unlike the selfish founder, however, the altruistic founder derives utility from transfers. Thus, the optimal deviation maximises the founder's objective function when $\theta_{1}=$ 0 : denote this deviation by $\tilde{t}_{1}\left(f_{1}\right)$ as it depends on organizational form choice.

Finally, consider the altruistic founder's optimal $\alpha \theta$-fraud. As, by Table 1 , this form of fraud is only threatening when $\theta_{0}=0$, we write the value of $t$ that maximises the founder's objective function under this form of fraud as $\hat{t}_{1}\left(f_{0}\right)$.

\section{B.1 High management costs}

In the high cost scenario, $\gamma=\frac{1}{2}$. This satisfies the conditions on cost functions imposed above, except inequality 12: here $c^{\prime}(2)=2>1$. The inequality was only used in lemmata 5 and 6 , which eliminated certain forms 
of fraud when at least one of the founders hired an low ability worker. We show, below, that the equilibrium in this model involves both founders hiring high ability workers; thus, violating this condition is not of consequence.

We therefore plot founders' returns as the stringency of non-profit regulation, $\rho$, varies. ${ }^{11}$ Doing so reveals an equilibrium in which both founder types found FPs and hire high ability workers for all levels of non-profit regulation, $\rho$ - a wage separating equilibrium. Founders' ensuing payoffs are displayed in Figure 4.

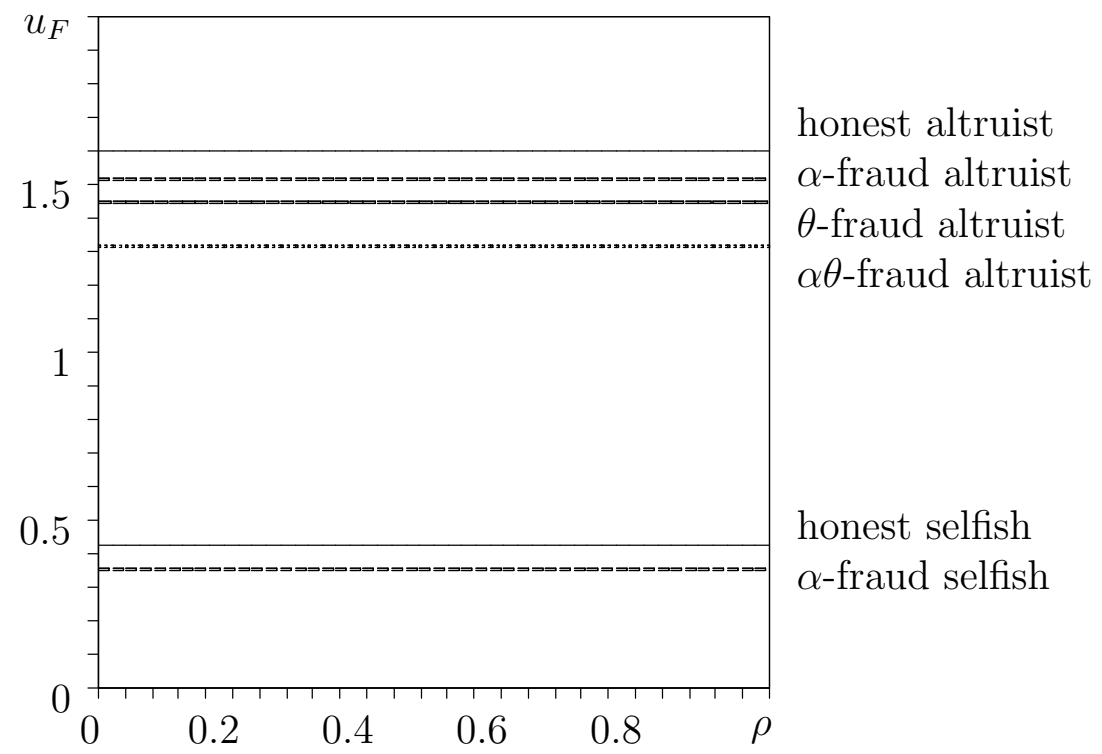

Figure 4: Founders' utility when $c(x)=\frac{1}{2} x^{2}$, both found FPs and hire high ability workers

The figure's upper four lines depict the altruist's utility under honesty (the solid line) and all three forms of fraud (pure $\alpha$, pure $\theta$ and $\alpha \theta$, in decreasing order of lucrativeness). The lower two lines depict the selfish founder's utility under honesty (the solid line) and $\alpha$-fraud: the costs of low ability are such that the two forms of $\theta$-fraud earn the selfish founder negative utility. (The fraudulent altruistic also does least well out of the forms of $\theta$ fraud.) All the lines are invariant in the stringency of non-profit regulation, $\rho$, as no non-profits are founded.

\footnotetext{
${ }^{11}$ The Maple code used to generate payoffs under all scenarios is available at www.economics.bham.ac.uk/rowat/research/0507rs-maple.zip.
} 
The figure shows that both founder types prefer honest behaviour for any value of $\rho$. For this to be an equilibrium, though, it must be that both founder types are maximising by their choice of organizational form and worker ability: the figure only depicts $f_{0}=f_{1}=1$ and $\theta_{0}=\theta_{1}=0$. Rather than display all permutations, we merely illustrate payoffs in the scenario reached if the altruistic founder chooses, instead, to found a NP. This is depicted in Figure 5. Thus, when the altruistic founder does not engage in any form of $\alpha$-fraud, thus founding a NP, her utility decreases as NP regulation becomes more stringent. Only when the selfish founder engages in $\alpha$-fraud does her utility decrease in $\rho$. Most importantly, the altruistic founder receives lower utility by founding a NP. Thus, this is not an equilibrium. Exploring all other combinations of worker abilities and organizational forms shows that neither founder type has an incentive to deviate from founder a FP and hiring a high ability worker.

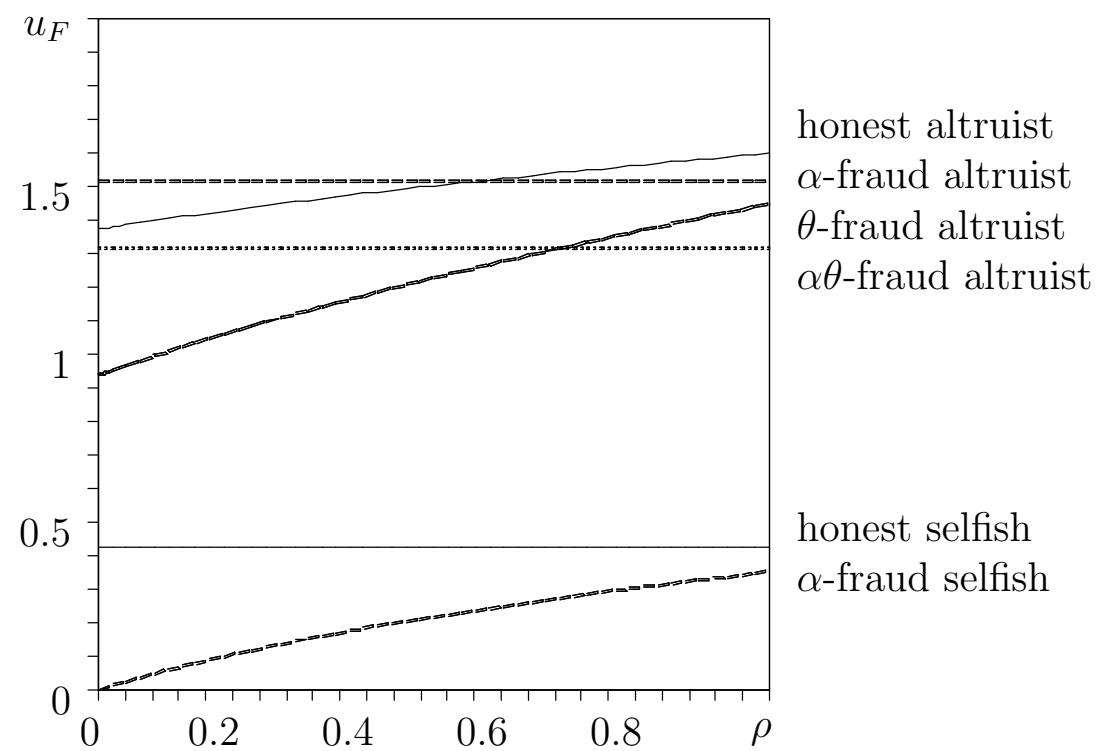

Figure 5: Founders' utility when $c(x)=\frac{1}{2} x^{2}$, only selfish founds FP; both hire high ability workers

\section{B.2 Low management costs}

Now set $\gamma=\frac{1}{10}$. Inequality 12 is now satisfied. Figure 6 shows founders' utility under the wage separating equilibrium. 


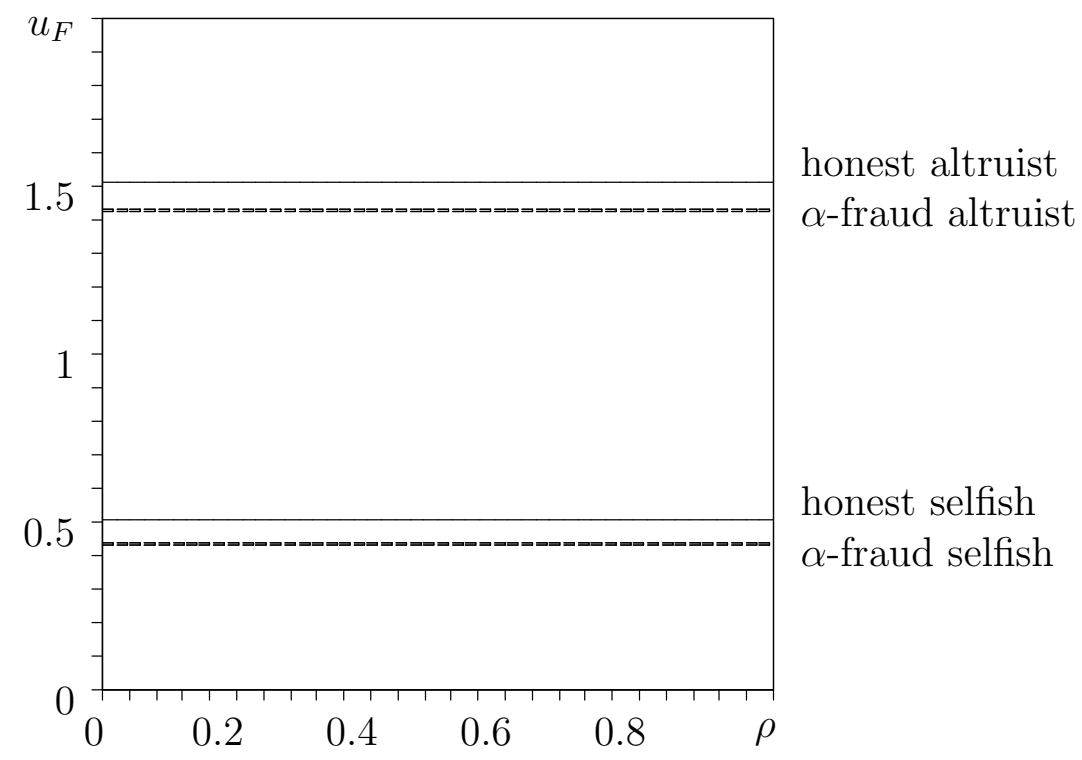

Figure 6: Founders' utility when $c(x)=\frac{1}{10} x^{2}$, both found FPs and hire low ability

\section{B.3 Moderate management costs}

Low let $\gamma=\frac{1}{4}$. Thus, inequality 12 is again satisfied.

The left panel of Figure 7 shows a separating equilibrium when $\rho$ is high: both founders found FPs, both hire low ability workers and both prefer honesty (the solid lines) to pure $\alpha$-fraud, the only deviation not eliminated by lemmata 5 and 6 . The altruistic founder prefers this to founding a NP (with either type of worker).

To see why the above is an equilibrium, note that the altruistic founder could earn a higher payoff by hiring a high ability worker, as depicted in the right panel of the figure. Intuitively, a high ability worker would let her set a higher transfer share, earning a larger donation. This, however, is not a separating equilibrium as it opens up new possibilities of fraud: upon hiring a high ability worker, she would do even better to engage in pure $\theta$-fraud (the top dotted line), pretending to have hired a high ability worker while actually hiring an low ability one. As the donor understands this, he knows that $\tilde{\theta}_{1}=1$ and $\tilde{t}_{1}<t_{1}$ and make a donation accordingly. When, however, the donor correctly infers that the altruistic founder has hired an low ability worker, the altruistic founder's optimal transfer is, by definition, $t_{1}$.

Even the selfish founder would earn greater utility by hiring a high ability 

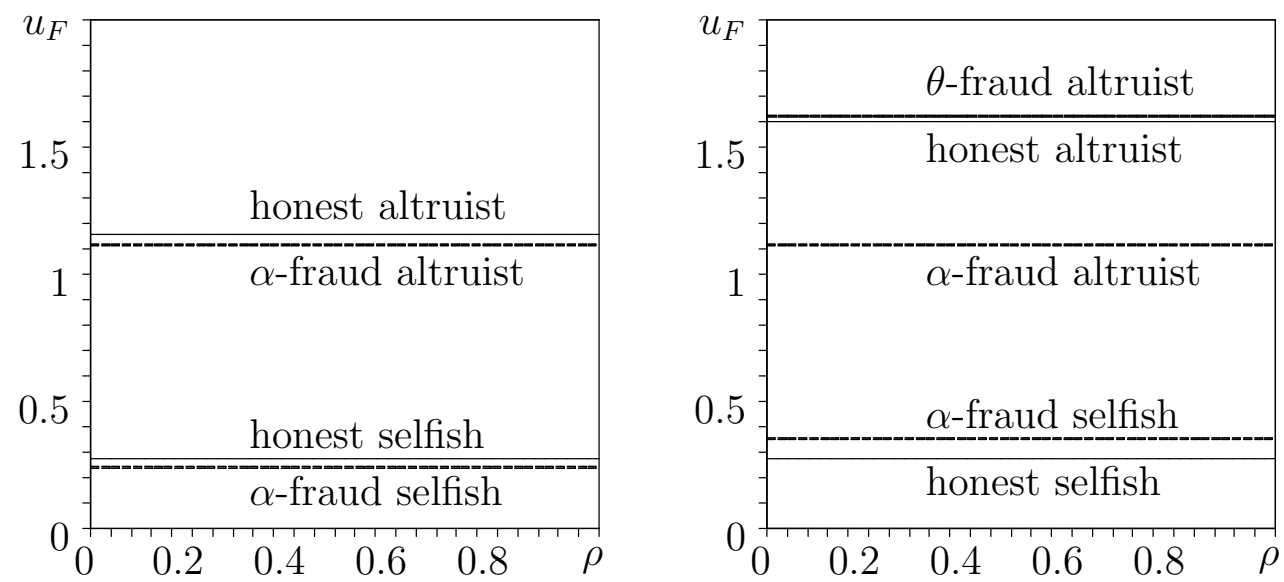

Figure 7: Founders' utility when $c(x)=\frac{1}{4} x^{2}$, both found FP

worker. However, if she did, the altruistic founder's returns to pure $\alpha$-fraud would exceed her returns to honesty, and the separating equilibrium would fail to exist.

For $\rho \in[\underline{\rho}, \bar{\rho}]$, Figure 8 illustrates the temptations facing both founder types: the dotted curve rising above the altruist's honesty curve as $\rho$ approaches one is that associated with pure $\theta$-fraud, while that exceeding honesty as $\rho$ decreases is that associated with pure $\alpha$-fraud.

While each founder prefers to deviate from this arrangement, neither can do so in a way that retains separation. Thus, any deviation will lead the donor to suspect fraud, leaving the founder worse off.

Finally, when NP regulation becomes very stringent, the objective function and IC constraints are illustrated by Figure 9 .

\section{References}

Mark Armstrong and Jean-Charles Rochet. Multi-dimensional screening: a user's guide. European Economic Review, 43(4-6):959 - 979, April 1999.

Timothy Besley and Maitreesh Ghatak. Competition and incentives with motivated agents. May 2003.

Andrea Buraschi and Francesca Cornelli. Donations. mimeo, 16 August 2003.

William Easterly. Can foreign aid buy growth? Journal of Economic Perspectives, 17(3):23 - 48, Summer 2003. 


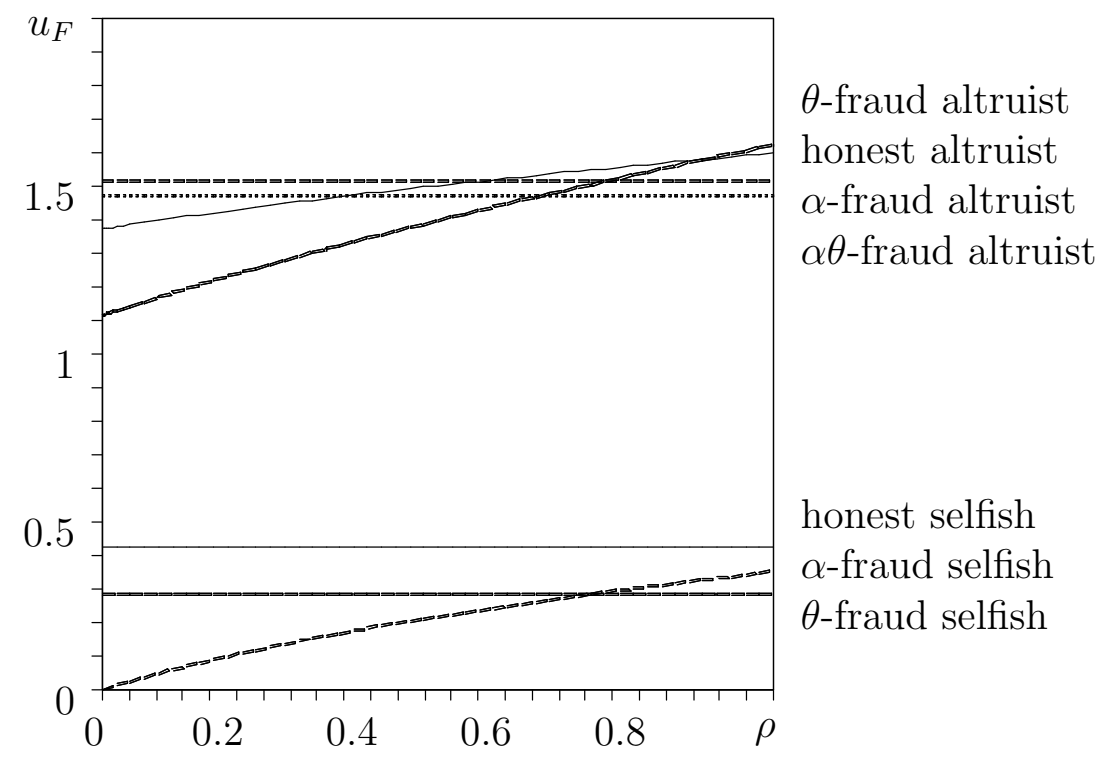

Figure 8: Founders' utility when $c(x)=\frac{1}{4} x^{2}$, only selfish founds FP, both hire high ability

Patrick François. Not-for-profit provision of public services. The Economic Journal, 113(486):C53 - C61, March 2003.

Robert H. Frank. What price the moral high ground? Southern Economic Journal, 63(1):1 - 17, July 1996.

Edward L. Glaeser and Andrei Shleifer. Not-for-profit entrepreneurs. Journal of Public Economics, 81:99 - 115, 2001.

Femida Handy and Eliakim Katz. The wage differential between nonprofit institutions and corporations: Getting more by paying less? Journal of Comparative Economics, 26:246 - 261, 1998.

Bruno Jullien, Bernard Salanié, and François Salanié. Screening risk-averse agents under moral hazard: Single-crossing and the CARA case. mimeo, September 2003.

Giovanni Maggi and Andrés Rodríquez-Clare. On countervailing incentives. Journal of Economic Theory, 66(1):238 - 263, June 1995.

Paul Milgrom and John Roberts. Price and advertising signals of product quality. Journal of Political Economy, 94(4):796 - 821, August 1986. 


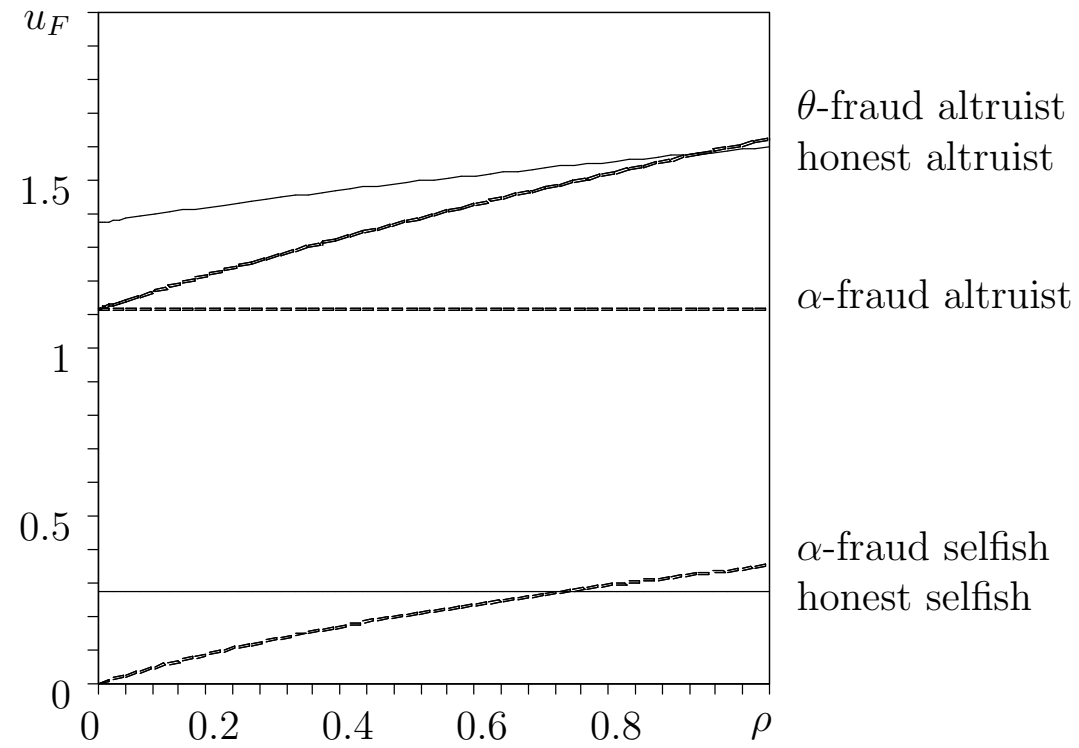

Figure 9: Founders' utility when $c(x)=\frac{1}{4} x^{2}$, only selfish founds FP and hires low ability

H. Naci Mocan and Erdal Tekin. Nonprofit sector and part-time work: an analysis of employer-employee matched data on child care workers. Review of Economics and Statistics, 85(1):38 - 50, February 2003.

Roger B. Myerson. Optimal coordination mechanisms in generalized principal-agent problems. Journal of Mathematical Economics, 10(1):67 - 81, June 1982.

Anne E. Preston. The nonprofit worker in a for-profit world. Journal of Labor Economics, 7(4):438 - 463, October 1989.

Ritva Reinikka and Jakob Svensson. Working for God? Discussion Paper 4214, CEPR, London, January 2004.

Christopher J. Ruhm and Carey Borkoski. Compensation in the nonprofit sector. mimeo, June 2002. 